\title{
NOTES
}

\section{Spontaneous Polymerization of Amphiphilic Vinyl Monomers V. Effect of Sodium Chloride on Spontaneous Polymerization of Sodium Dodecyl 2-Hydroxy-3-methacryloyloxypropyl Phosphate}

\author{
Yutaka YaSUdA, ${ }^{*}$ Katsuhiko Rindo, and Shuzo Aoki ${ }^{\dagger}$ \\ Wakayama Research Laboratories, Kao Corporation, 1334 Minato, Wakayama 640, Japan
}

(Received May 27, 1993)

\begin{abstract}
KEY WORDS Spontaneous Polymerization / Amphiphilic Vinyl Monomer /
Radical Polymerization / Monomer Aggregation / Micelle /
\end{abstract}

In the previous papers of this series, ${ }^{1-4}$ we have reported on the spontaneous polymerization of some amphiphilic vinyl monomers, such as sodium alkyl 2-hydroxy-3-methacryloyloxypropyl phosphate $\left(\mathrm{C}_{n}\right.$-AHMP) and alkyl-2methacryloyloxyethyldimethylammonium bromide, in which the polymerization takes place under the formation of monomer aggregates, e.g., micelles or inverse micelles, through radical mechanism in the absence of conventional initiators. The aggregation state of monomer is a dominant factor to control the spontaneous polymerizability, i.e., the generation of initiating radical species. The measurement of ${ }^{1} \mathrm{H}$ spin-lattice relaxation time $\left(T_{1}\right)$ of amphiphilic monomers in $\mathrm{D}_{2} \mathrm{O}$ provides the information of their molecular motion related to the monomer aggregation state. ${ }^{2,3}$ Addition of an inorganic electrolyte, sodium chloride, to the micellar solution of lowreactive $\mathrm{C}_{8}$-AHMP increased the spontaneous polymerizability to produce the polymer quantitatively at $35^{\circ} \mathrm{C}$, and this behavior was related to the decrease of $T_{1}$ values with increasing amount of $\mathrm{NaCl}$ added. ${ }^{3}$

In connection with elucidation of the relation between monomer aggregation state and spontaneous polymerizability, the present report deals with the modification of micellar state of sodium dodecyl 2-hydroxy-3-methacryloyloxypropyl phosphate $\left(\mathrm{C}_{12}\right.$-AHMP), having the highest spontaneous polymerizability among $\mathrm{C}_{n}$-AHMP, ${ }^{2}$ by adding $\mathrm{NaCl}$.

\section{EXPERIMENTAL}

The monomer, $\mathrm{C}_{12}$-AHMP, prepared and characterized previously, ${ }^{1}$ was used. Measurement of $T_{1}$ and polymerization experiments were carried out in the same manner as previously described. ${ }^{1,2}$

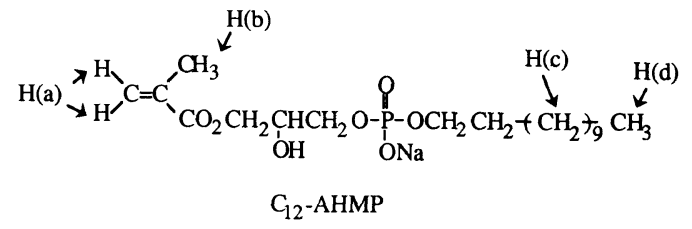

\section{RESULTS AND DISCUSSION}

Table I shows the effect of $\mathrm{NaCl}$ on the polymerization of $\mathrm{C}_{12}$-AHMP without initiator in water. Without adding $\mathrm{NaCl}$, the monomer polymerized spontaneously as has

\footnotetext{
* To whom correspondence should be addressed.

† Present address: Department of Applied Chemistry, Faculty of Engineering, Osaka City University, Sumiyoshi-ku, Osaka 558, Japan.
} 
Table I. Effect of sodium chloride on the polymerization of $\mathrm{C}_{12}$-AHMP in water without initiator: $\left[\mathrm{C}_{12}-\mathrm{AHMP}\right]=50 \mathrm{mmoll}^{-1}$

\begin{tabular}{|c|c|c|c|}
\hline $\mathrm{NaCl}$ & $\mathrm{Temp}^{\mathrm{a}}$ & Time & Polymer yield ${ }^{\mathrm{b}}$ \\
\hline $\mathrm{mmoll}^{-1}$ & ${ }^{\circ} \mathrm{C}$ & $\mathrm{h}$ & $\%$ \\
\hline \multirow[t]{2}{*}{0} & r.t. & 21 & 72 \\
\hline & 80 & 2.5 & 100 \\
\hline \multirow[t]{2}{*}{0.1} & r.t. & 21 & 0 \\
\hline & 80 & 2.5 & 19 \\
\hline \multirow[t]{3}{*}{0.3} & r.t. & 21 & 0 \\
\hline & & 720 & 88 \\
\hline & 80 & 2.5 & 50 \\
\hline \multirow[t]{2}{*}{0.5} & r.t. & 21 & 0 \\
\hline & 80 & 2.5 & 0 \\
\hline \multirow[t]{2}{*}{1.0} & r.t. & 21 & 0 \\
\hline & 80 & 2.5 & 0 \\
\hline
\end{tabular}

a r.t., room temperature $\left(25-30^{\circ} \mathrm{C}\right)$.

b Determined by UV-method. ${ }^{1}$

Table II. Effect of sodium chloride on the ${ }^{1} \mathrm{H}$ spine-lattice relaxation time $\left(T_{1}\right)$ of $\mathrm{C}_{12}$-AHMP in $\mathrm{D}_{2} \mathrm{O}$ at $30^{\circ} \mathrm{C}^{\mathrm{a}}$

\begin{tabular}{|c|c|c|c|c|}
\hline \multirow{3}{*}{$\frac{\mathrm{NaCl}}{\mathrm{mmoll}^{-1}}$} & \multicolumn{4}{|c|}{$\frac{T_{1}}{\mathrm{~ms}}$} \\
\hline & $\mathrm{H}(\mathrm{a})$ & $\mathrm{H}(\mathrm{b})$ & $\mathrm{H}(\mathrm{c})$ & $\mathrm{H}(\mathrm{d})$ \\
\hline & $\delta: 6.12$ & 1.93 & 1.28 & $\begin{array}{c}0.88 \\
\text { in ppm }\end{array}$ \\
\hline 0 & 659 & 1078 & 748 & 1598 \\
\hline 0.1 & 633 & 1038 & 738 & 1551 \\
\hline 0.3 & 617 & 997 & 732 & 1485 \\
\hline 0.5 & 586 & 1020 & 703 & 1404 \\
\hline 1.0 & 583 & 820 & 744 & 1094 \\
\hline
\end{tabular}

${ }^{\mathrm{a}}\left[\mathrm{C}_{12}-\mathrm{AHMP}\right]=50 \mathrm{mmoll}^{-1}$ in the presence of $p$ benzoquinone $1000 \mathrm{ppm}$.

been reported. ${ }^{1}$ Addition of $\mathrm{NaCl}$ in the concentration range from 0.1 to $0.3 \mathrm{mmoll}^{-1}$ inhibited the polymerization at a room temperature, though long time standing produced the polymer at last, and suppressed the formation of polymer at a higher temperature, $80^{\circ} \mathrm{C}$. Further increase of added $\mathrm{NaCl}$ inhibited the polymerization even at
Table III. Relation between the $T_{1}$ values of terminal methyl protones and the spontaneous polymerizability of $C_{n}$-AHMP in water

\begin{tabular}{|c|c|c|c|c|c|}
\hline \multirow{2}{*}{$\frac{\mathrm{C}_{n}-\mathrm{AHMP}}{\mathrm{mmol}^{-1}}$} & \multirow{2}{*}{$\frac{[\mathrm{NaCl}]}{\mathrm{mmoll}^{-1}}$} & \multirow{2}{*}{$\frac{T_{1}^{\mathrm{a}}}{\mathrm{ms}}$} & \multicolumn{3}{|c|}{$\begin{array}{c}\text { Spontaneous } \\
\text { polymerizability }^{\mathbf{b}}\end{array}$} \\
\hline & & & $35^{\circ} \mathrm{C}$ & $60^{\circ} \mathrm{C}$ & $80^{\circ} \mathrm{C}$ \\
\hline$C_{8}: 100$ & 0 & 1882 & $x$ & 0 & \\
\hline$: 100$ & 0.1 & 1619 & 0 & & \\
\hline$C_{12}: 5$ & 0 & 1608 & 0 & & \\
\hline$: 50$ & 0 & 1598 & 0 & & \\
\hline$: 50$ & 0.5 & 1404 & & & $x$ \\
\hline$: 100$ & 0 & 1391 & 0 & & \\
\hline $\mathrm{C}_{14}: 5$ & 0 & 1285 & & $x$ & 0 \\
\hline $\mathrm{C}_{16}: 5$ & 0 & 1242 & & & $x$ \\
\hline : 5 & $5^{c}$ & 1600 & & 0 & \\
\hline
\end{tabular}

a Determined in $\mathrm{D}_{2} \mathrm{O}$ at $30^{\circ} \mathrm{C}$.

b Polymerization activity without initiator in water. ${ }^{1-3}$

c Sodium dodecylglyceryl phosphate was added instead of $\mathrm{NaCl}$.

$80^{\circ} \mathrm{C}$. These results suggested that the presence of $\mathrm{NaCl}$ modified the monomer aggregation state to check the generation of initiating radical species, contrary to the case of $\mathrm{C}_{8}$-AHMP. ${ }^{3}$ As shown in Table II, the increase of $\mathrm{NaCl}$ added decreased the $T_{1}$ values, especially those of terminal methyl protons in long chain alkyl.

Table III shows the comparison of the $T_{1}$ values of $\mathrm{C}_{n}$-AHMP, having different alkyl chain, with the spontaneous polymerizabilities in the absence and presence of $\mathrm{NaCl}$. The $T_{1}$ values decreased with increasing alkyl chain length and adding $\mathrm{NaCl}$ at the same monomer concentration, indicating that the molecular motion of the monomer was suppressed in the micelle. The spontaneous polymerizability of $\mathrm{C}_{n}$-AHMP is governed by alkly chain length, and dodecyl group gives the highest polymerizability, i.e., the highest activity in the generation of initiating radical species. Thus, the occurrence of spontaneous polymerization requires an appropriate freedom of molecular motion in the monomer aggregates, in which longer alkyl chain gives more tightly packed state, and the presence of inorganic electrolyte, 


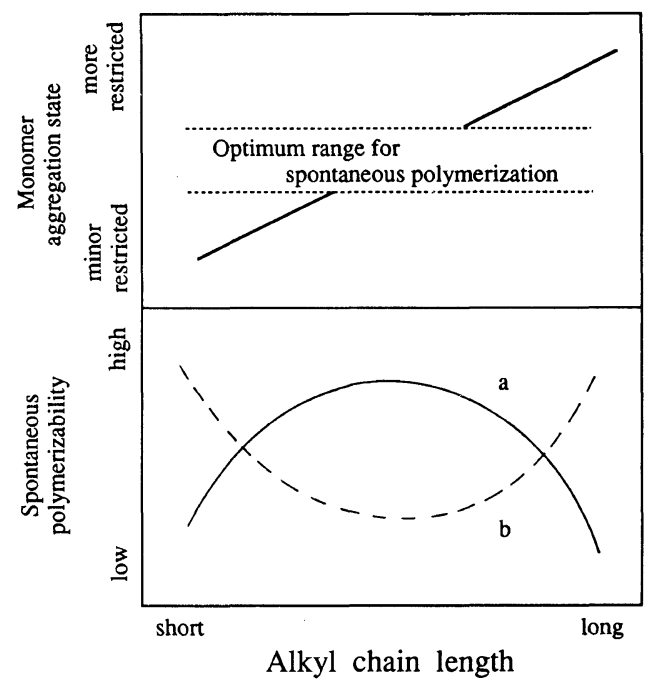

Figure 1. Conceptual illustration of the spontaneous polymerization of amphiphilic monomers in the micellar solution: a, original reactivity; b, modified reactivity with additives.

$\mathrm{NaCl}$, leads to more restricted state of the monomer aggregation to change the monomer reactivity. Another way to change the monomer aggregation state is the addition of a surfactant being able to form a mixed-micelle. Addition of equimolar amount of sodium dodecylglyceryl phosphate to the micellar solution of non-reactive $\mathrm{C}_{16}$-AHMP increased the $T_{1}$ value of terminal methyl protons and converted it to be high reactive. ${ }^{3}$

The discussion described above is summarized in Figure 1, as conceptual illustration.

Lingnau and Meyerhoff have proposed the thermal initiation mechanism of methyl methacrylate, in which the dimer diradical is formed spontaneously from the monomer molecules followed by chain-transfer reaction giving the dimer monoradical as initiating species. ${ }^{5-7}$ The present polymerization system is assumed to follow the similar mechanism, and the suitable monomer aggregation state is considered to facilitate the reaction step giving diradical and/or monoradical. Further discussion will be presented in a future publication.

\section{REFERENCES}

1. Y. Yasuda, K. Rindo, and S. Aoki, Makromol. Chem., 193, 2875 (1992).

2. Y. Yasuda, K. Rindo, R. Tsushima, and S. Aoki, Makromol. Chem., 194, 485 (1993).

3. Y. Yasuda, K. Rindo, R. Tsushima, and S. Aoki, Makromol. Chem., 194, 1619 (1993).

4. Y. Yasuda, K. Rindo, R. Tsushima, and S. Aoki, Makromol. Chem., 194, 1893 (1993).

5. J. Lingnau and G. Meyerhoff, Polymer, 24, 1473 (1983).

6. J. Lingnau and G. Meyerhoff, Makromol. Chem., 185, 587 (1984).

7. J. Lingnau and G. Meyerhoff, Macromolecules, 17, 941 (1984). 